\title{
Effect of tryptophan administration on tryptophan, 5-hydroxyindoleacetic acid and indoleacetic acid in human lumbar and cisternal cerebrospinal fluid
}

\author{
SIMON N YOUNG A ND SERGE GAUTHIER \\ From the Departments of Psychiatry, and of Neurology and Neurosurgery, McGill University \\ and the Montreal Neurological Hospital, Montreal, Quebec, Canada
}

SUMMARY Tryptophan, 5-hydroxyindoleacetic acid and indoleacetic acid were measured in cerebrospinal fluid taken during pneumoencephalography from patients, some of whom took a $3 \mathrm{~g}$ or $6 \mathrm{~g}$ tryptophan load at various times before. Measurements were made on both lumbar and cisternal cerebrospinal fluid and the results showed similarities between indoleamine metabolism in human brain and spinal cord. Our data suggested that (1) the blood-brain barrier active transport system for tryptophan is not far from saturation with tryptophan and the rate-limiting enzyme in 5-hydroxytryptamine (5HT) synthesis, tryptophan hydroxylase, is about half saturated. Therefore, both $3 \mathrm{~g}$ and $6 \mathrm{~g}$ tryptophan loads produced the same maximum rise in $5 \mathrm{HT}$ synthesis of just under $100 \%$, (2) tryptamine differs from $5 \mathrm{HT}$ in two respects. It is more sensitive to changes in tryptophan availability than $5 \mathrm{HT}$ and the $6 \mathrm{~g}$ load increased brain tryptamine metabolism more than the $3 \mathrm{~g}$ load; also some of the tryptamine in brain is derived from peripheral sources and diffuses from blood to brain, (3) although the brain tryptamine content is much lower than that of 5HT, its rate of metabolism as indicated by CSF metabolite levels is not. In controls the rate of tryptamine metabolism is $15 \%$ of the rate of $5 \mathrm{HT}$ metabolism and this can increase to $40 \%$ after a $6 \mathrm{~g}$ tryptophan load.

The concentrations of tryptophan and 5-hydroxyindoleacetic acid (5HIAA) in human ventricular, ${ }^{12}$ cisternal and lumbar ${ }^{3}$ cerebrospinal fluid (CSF) are positively correlated. As CSF tryptophan reflects the CNS content of this amino acid, ${ }^{4}$ and CSF 5HIAA reflects CNS 5-hydroxytryptamine (5HT) turnover, ${ }^{5}{ }^{6}$ these data indicate that tryptophan concentration is one of the factors that controls 5HT turnover in most areas of the human CNS. Tryptophan availability also seems to be one of the factors controlling human CNS tryptamine metabolism, as the concentrations in CSF of tryptophan and of the tryptamine metabolite indoleacetic acid (IAA) also are correlated. ${ }^{3}$ When humans are given a tryptophan load CSF 5HIAA rises $^{7}$ and the concentration of tryptophan and 5HIAA in CSF are related. ${ }^{8}$ The data for rats

Address for reprint requests: Dr Simon N Young, Department of Psychiatry McGill University, 1033 Pine Avenue West Montreal, Quebec, Canada H3A 1 A 1 .

Accepted 20 November 1980 indicate that, if the size of the tryptophan load increases, tryptophan hydroxylase becomes saturated and CSF 5HIAA does not rise further. However, tryptamine metabolism appeared to be more sensitive to tryptophan administration since CSF IAA increased linearly with the size of a tryptophan load. ${ }^{9}$ The present study was designed to test whether the control of indoleamine metabolism in human CNS is similar to that in the rat, by measuring CSF tryptophan, 5HIAA and IAA in humans who received 3 or $6 \mathrm{~g}$ of tryptophan.

\section{Methods}

The study, performed on patients undergoing diagnostic pneumoencephalography (PEG) at the Montreal Neurological Hospital, was approved by the ethics committees of the Montreal Neurological Hospital and the Department of Psychiatry, McGill University. The purpose of the study was explained to 40 patients and they were asked if 
they would be willing to take tablets which contained tryptophan or placebo, before their PEG. The 38 patients who agreed to participate in the study signed consent forms. Of these 38 patients, 16 received $3 \mathrm{~g} \mathrm{~L}$-tryptophan (six tablets of $500 \mathrm{mg}$ ), 16 received $6 \mathrm{~g}$ (12 tablets) and six received placebo (six tablets) at $8 \pm 1$ or $12 \pm 1$ hours before the PEG was started. The procedure was done on the fasting patients, without premedication, between $9.00 \mathrm{am}$ and 12 noon. The first $2 \mathrm{ml}$ of CSF was used for routine diagnostic purposes and the next 2 to $6 \mathrm{ml}$ were collected for analysis of indoles. This sample was derived from the lumbar sac, which in humans has a volume of about $15 \mathrm{ml}^{10}$ and will be referred to in this study as lumbar CSF. Oxygen was then injected until the lateral ventricles contained oxygen. Some CSF from this compartment was thus displaced down into the basal cisterns, and when most of the oxygen had been injected (average $60 \mathrm{ml}$ ) a second sample of CSF (6 to $8 \mathrm{ml}$ ) was collected through the lumbar needle. This last sample consisted mainly of fluid that was originally in the basal cisterns and was displaced into the lumbar sac. It is referred to in this study as cisternal CSF. No more than 30 minutes separated the collection of lumbar and cisternal CSF. Both samples were allowed to drip directly from the needle into acid-washed tubes, and were stored at $-70^{\circ} \mathrm{C}$ until the analyses were performed. Blood samples were collected, into a heparinised evacuated tube, from some of the patients, 10 minutes before the collection of lumbar CSF.

Indoles in CSF were measured by the method of Anderson and Purdy. ${ }^{11}$ This method involves direct injection of 10 to $50 \mu \mathrm{l}$ of CSF in a high

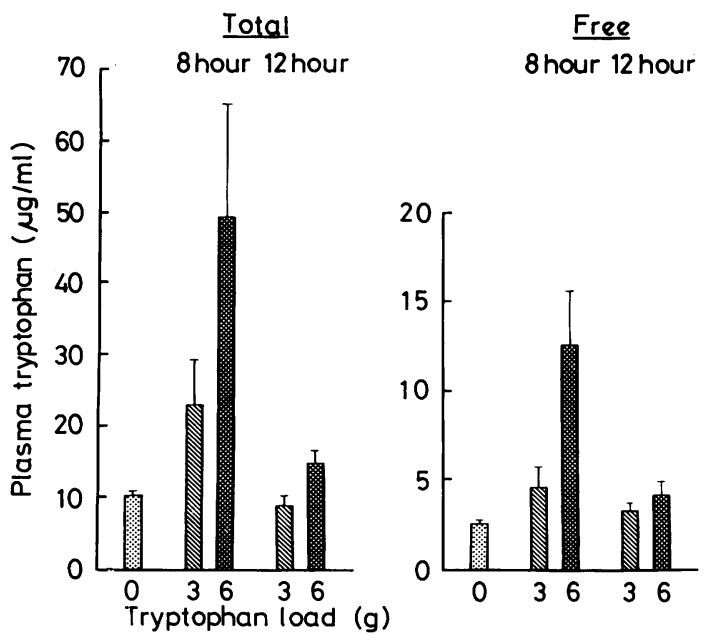

performance liquid chromatograph, separation of the various compounds on a reverse-phase column $(30 \mathrm{~cm} \times 3.9 \mathrm{~mm}$ column of $10 \mu$ " $\mu$-Bondapack $\mathrm{C}_{18}$ " from Waters Associates Inc, Milford, MA USA) and measurement of the fluorescence of the indole ring using a modified Aminco-Fluoromonitor (American Instrument Co, Silver Spring, MD, USA). The blood was used for the determination of total and free (non-albumin-bound) plasma tryptophan. The tryptophan concentration in an ultrafiltrate of plasma was taken as the free plasma tryptophan concentration. The ultrafiltrate was obtained with an Amicon propellant-pressurised ultrafiltration cell with UM 10 membranes (nominal molecular weight cut-off 10000 ) at $37^{\circ} \mathrm{C}$ and $\mathrm{pH} 7 \cdot 4$. Tryptophan in plasma and ultrafiltrate was measured by the method of Denckla and Dewey. ${ }^{12}$

\section{Patients}

Measurements were made on samples from 66 patients. Information on the patients, including some characteristics known to affect indoleamine metabolism are given in the table. These data are dealt with in the discussion. The majority of the

Table Patient characteristics

\begin{tabular}{llll}
\hline $\begin{array}{l}\text { Tryptophan } \\
\text { treatment }\end{array}$ & $\begin{array}{l}\text { Age } \\
\text { (mean and } \\
\text { range) } \\
(y r)\end{array}$ & Female/Male & $\begin{array}{l}\text { On } \\
\text { anticonvulsants/ } \\
\text { others }\end{array}$ \\
\hline Control & $33(18-65)$ & $18 / 16$ & $21 / 13$ \\
$3 \mathrm{~g}, 8 \mathrm{hr}$ & $34(18-54)$ & $4 / 4$ & $2 / 6$ \\
$6 \mathrm{~g}, 8 \mathrm{hr}$ & $30(24-41)$ & $7 / 2$ & $7 / 2$ \\
$3 \mathrm{~g}, 12 \mathrm{hr}$ & $30(24-42)$ & $8 / 0$ & $5 / 3$ \\
$6 \mathrm{~g}, 12 \mathrm{hr}$ & $39(21-63)$ & $3 / 4$ & $5 / 2$ \\
\hline
\end{tabular}

Fig 1 The influence of tryptophan administration on plasma tryptophan concentrations. L-Tryptophan $(3 \mathrm{~g}$ or $6 \mathrm{~g}$ ) was given orally 8 or 12 hours before blood was taken. The values are given as mean $\pm S E$. The control (zero time) values are 10.0 $\pm 0.6 \mu \mathrm{g} / \mathrm{ml}$ for total and $2.57 \pm 0.21$ for free plasma tryptophan. The number of determinations are as follows: Controls, 13; $3 \mathrm{~g} 8$ hours, 5; $6 \mathrm{~g} 8$ hours, 7; $6 \mathrm{~g}$ 12 hours, 7. Using a one-tailed t-test the $6 \mathrm{~g}$ load produced higher values than the $3 \mathrm{~g}$ load for free plasma tryptophan at 8 hours $(p<0.05)$ and for total plasma tryptophan at 12 hours $(p<0 \cdot 005)$. 
patients were epileptic receiving anticonvulsants, although there were some whose anticonvulsant medication had been withdrawn at least one week before pneumoencephalography as part of their investigation in hospital, and some non-epileptic patients. All the epileptic patients were suffering from complex partial seizures but none of them had a seizure in the 24 hours preceding the PEG. Tryptophan treatment did not precipitate a seizure in any of the patients. The most common diagnosis among those without epilepsy was pituitary chromophobe adenoma, but there were also patients with other tumours and other miscellaneous diagnoses.
Results

We made determinations on samples from six patients who received placebo and on a further 27 patients who received no tablets. The mean values for these two groups did not differ and the values for all 35 patients were pooled to give control values. We felt this was justified because of the lack of difference between the two groups and because, even if indoleamine metabolism in humans was influenced by stress, the stress of being woken to take tablets would be small compared with that of undergoing PEG.
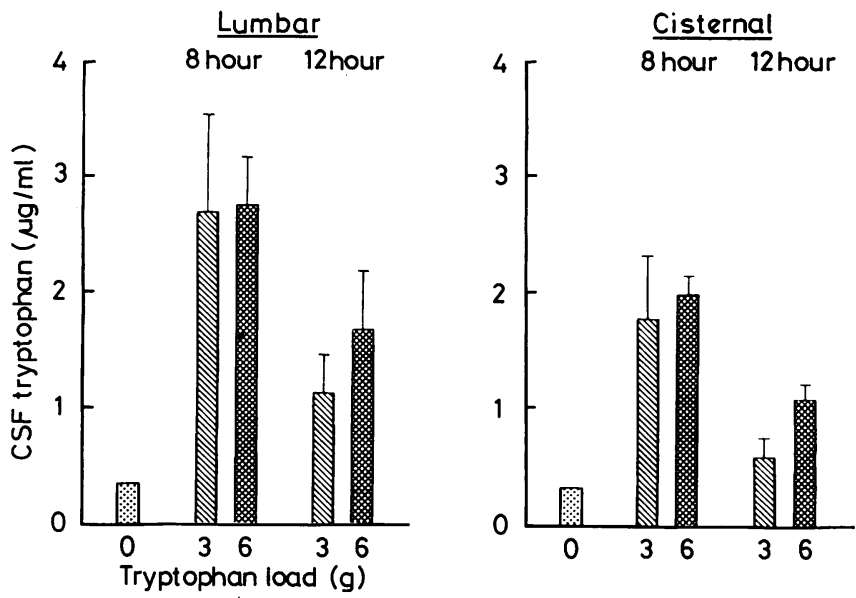

Fig 2 The influence of $3 \mathrm{~g}$ and $6 \mathrm{~g}$ tryptophan loads on CSF tryptophan concentrations. Details are given in the text and caption in fig 1. The control values for cisternal and lumbar CSF are $0.301 \pm 0.017$ and $0.330 \pm 0.017 \mathrm{ng} / \mathrm{ml}$ respectively. The number of determinations are: cisternal controls, 34; lumbar controls, 33; 8 hours $3 \mathrm{~g}$ cisternal and lumbar, $8 ; 8$ hours $6 \mathrm{~g}$ cisternal, 8; 8 hours 6 g lumbar, 9; 12 hours $3 \mathrm{~g}$ cisternal and lumbar, 8 ; 12 hours $3 \mathrm{~g}$ cisternal and lumbar, 7. The $6 \mathrm{~g}$ load produced higher cisternal CSF tryptophan concentrations than the $3 \mathrm{~g}$ load at 12 hours $(p<0.005)$.
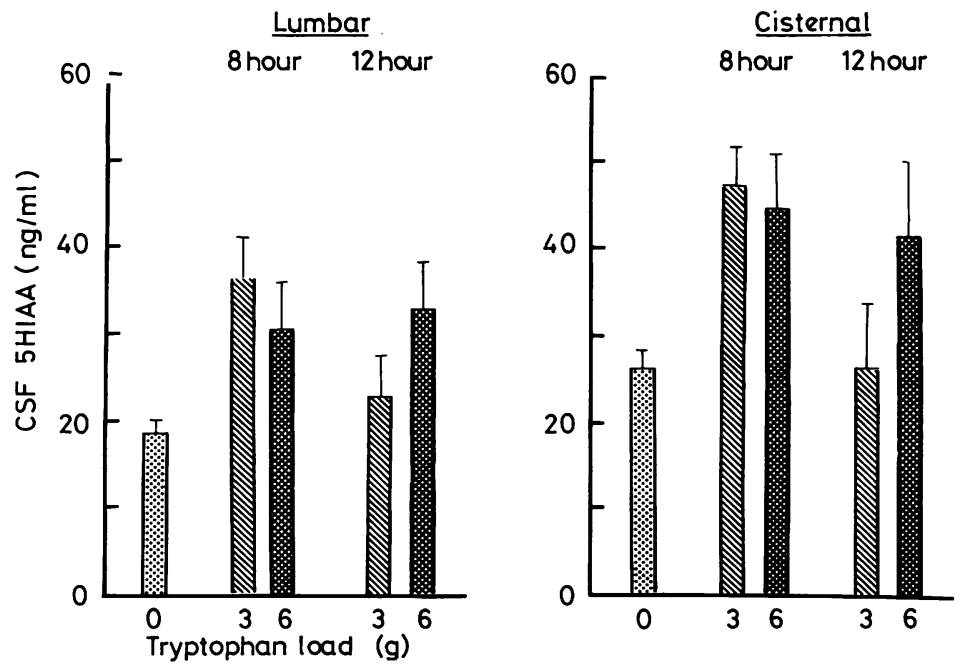

Fig 3 The influence of $3 \mathrm{~g}$ and $6 \mathrm{~g}$ tryptophan loads on $\mathrm{CSF}$ 5HIAA concentrations. Details are given in the text and caption of fig 1. The number of determinations are the same as in fig 2 except that there were only 7 determinations for the cisternal samples at 8 hours after the $3 \mathrm{~g}$ load. None of the differences between $3 \mathrm{~g}$ and $6 \mathrm{~g}$ were statistically significant. 

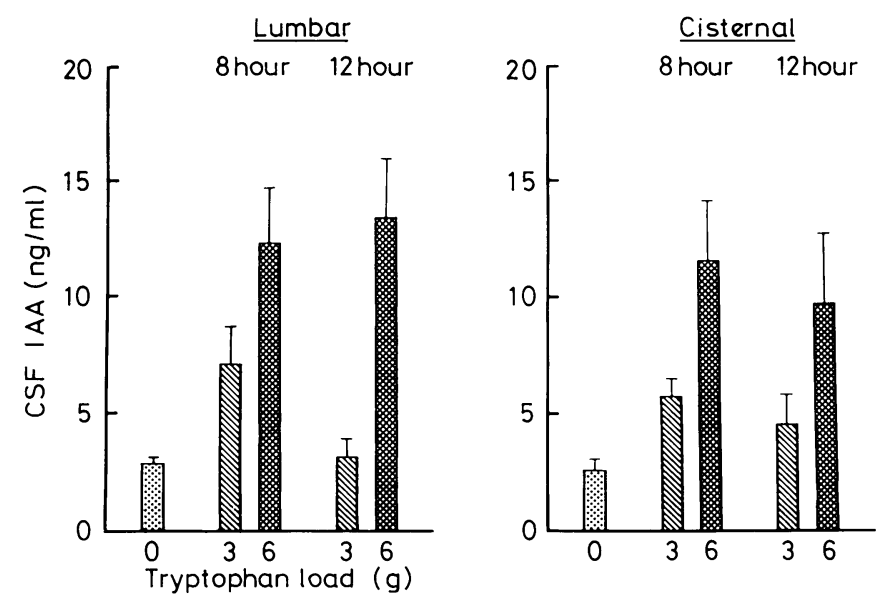

Fig 4 The influence of $3 g$ and $6 \mathrm{~g}$ tryptophan loads on CSF IA A concentrations. Details are given in the text and caption to fig 1. Control value.; for cisternal and lumbar CSF are $2.59 \pm 0.43$ and $2.82 \pm 0.34 \mathrm{ng} / \mathrm{ml}$ respectively. The number of determinations are the same as in fig 2. The $6 \mathrm{~g}$ load produced higher CSF IA A values in the cisternal and lumbar samples at 8 hours $(p<0.05)$ and in the lumbar samples at 12 hours $(\mathrm{p}<0.005)$.

Data are presented for plasma tryptophan (fig 1), CSF tryptophan (fig 2), CSF 5HIAA (fig 3) and CSF IAA (fig 4). Each figure gives data for control patients and patients who received a $3 \mathrm{~g}$ or $6 \mathrm{~g}$ tryptophan load eight hours or 12 hours before CSF was taken.

The rise of plasma tryptophan in patients receiving tryptophan loads was quite variable (fig 1). We have also found this in depressed patients on chronic tryptophan treatment. ${ }^{13}$ The variability is not due to the difference in doses that the patients received on a $\mathrm{mg} / \mathrm{kg}$ basis as there was no relationship between plasma tryptophan and weight of the patients. Presumably there is variability between patients in the rate at which tryptophan is catabolised in the liver by tryptophan pyrrolase. Figure 1 shows that both sizes of tryptophan load increased plasma tryptophan, the increase being larger for the $6 \mathrm{~g}$ than for the $3 \mathrm{~g}$ load. For CSF tryptophan (fig 2) there was no difference between the values for the large and small load at eight hours but there was at twelve hours, when the tryptophan content of body fluids was declining. The rise of CSF 5HIAA (fig 3), which increased slightly less than two-fold in both lumbar and cisternal samples, was relatively modest. There was no difference between the effect of the $3 \mathrm{~g}$ and $6 \mathrm{~g}$ loads but there was a tendency for the $6 \mathrm{~g}$ load to give higher values at 12 hours when the rise of CSF 5HIAA produced by the $3 \mathrm{~g}$ load was declining. At both eight and twelve hours the rise in CSF IAA was greater with $6 \mathrm{~g}$ tryptophan than with $3 \mathrm{~g}$ (fig 4). Tryptophan loading produced similar results in cisternal and lumbar samples.

\section{Discussion}

Because the tryptophan loads were given at random, the groups were not well matched for sex and for treatment with anticonvulsants (table), two factors which are known to influence indoleamine metabolism. ${ }^{3}$ The differences caused by these factors are small compared with the changes produced by tryptophan administration and the uneven distribution between the groups does not affect any of the conclusions in this study. Thus, anticonvulsants lower 5HIAA but only in lumbar CSF. ${ }^{3}$ However, the pattern of results in this study is similar in CSF from lumbar and cisternal compartments. Tryptophan, 5HIAA and IAA tend to be higher in CSF from females than males. In the eight hours' samples there are more females in the $6 \mathrm{~g}$ group than in the $3 \mathrm{~g}$ group. This would tend to make the values higher for the $6 \mathrm{~g}$ group and yet there was no difference for tryptophan and 5HIAA between the two groups at eight hours (figs 2 and 3). At twelve hours there are more women in the $3 \mathrm{~g}$ group but this did not prevent elevated levels of tryptophan and IAA in the $6 \mathrm{~g}$ group compared with the $3 \mathrm{~g}$ at twelve hours (figs 2 and 4). Thus, the interpretation of the results is not altered by the mismatching of the groups.

One surprising aspect of our results is that the maximum ( 8 hour) CSF tryptophan values were not higher after $6 \mathrm{~g}$ tryptophan than after $3 \mathrm{~g}$, even though the larger load gave higher plasma tryptophan concentrations (figs 1 and 2). This may reflect partly the variability of the results but it may 
also provide information on blood-brain barrier transport of tryptophan in humans. We have siudied tryptophan uptake across the blood-brain barrier in the rat and found saturable and nonsaturable (presumably diffusion) components. ${ }^{14}$ At physiological tryptophan concentrations the saturable system was about half saturated and the diffusion component was relatively small. Thus, increases in tryptophan concentration produced relatively modest increases in the rate of tryptophan uptake. If the situation in humans is similar, the increase in the rate of transport of tryptophan from blood to brain, when the size of load is increased from $3 \mathrm{~g}$ to $6 \mathrm{~g}$, might be small. This might explain why there is no rise in CSF tryptophan in these circumstances.

The rise of CSF tryptophan at eight hours was six to eight-fold (fig 2), while that of 5HIAA was about two-fold (fig 3). The rise of CSF 5HIAA seen by Eccleston et al ${ }^{7}$ eight hours after patients received a tryptophan load of $50 \mathrm{mg} / \mathrm{kg}$ was similar. These data indicate that tryptophan hydroxylase in human CNS is about half saturated. In this respect humans are like rats whose brain tryptophan concentration is close to the $\mathrm{Km}$ for tryptophan hydroxylase. ${ }^{15} 16$ Thus, even if much larger tryptophan loads had been given the rise of CSF 5HIAA is unlikely to have been greater.

The data in fig 4 shows that CNS tryptamine metabolism changes in response to tryptophan availability. Thus, while the smaller load increased IAA $2 \cdot 2$-fold in cisternal CSF at eight hours, $6 \mathrm{~g}$ tryptophan increased it $4 \cdot 4$-fold. In a study on rats we also found that tryptamine metabolism was more responsive than $5 \mathrm{HT}$ metabolism to changes in tryptophan availability. ${ }^{9}$ Our present data on humans suggest that, as in the rat, the degree of saturation of aromatic amino acid decarboxylase with tryptophan is less than that of tryptophan hydroxylase.

At eight hours after the load, CSF IAA was higher in the patients who received $6 \mathrm{~g}$ tryptophan than in those who received $3 \mathrm{~g}$, even though there was no difference in the CSF tryptophan concentrations at this time. There are two factors that could contribute to this result. Firstly, the larger tryptophan load might have given higher CNS tryptophan levels at earlier times. Obviously it will take some time for the tryptophan to be metabolised to tryptamine and thence to IAA and for the IAA to diffuse from tissue to CSF. Secondly, our studies in the rat have shown that some of the tryptamine in CNS is derived from peripheral

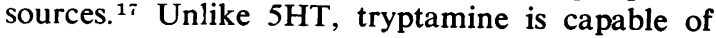

crossing the blood-brain barrier. In the patients who received the larger tryptophan load, plasma tryptophan and presumably the tryptophan content of peripheral tissues, was higher at eight hours. This would increase tryptamine synthesis in the kidney and liver, and tryptamine formed in those tissues would augment the brain levels. We have shown that in patients with cirrhosis of the liver CSF IAA can be as high as $40 \mathrm{ng} / \mathrm{ml}$ even though CSF tryptophan is no more elevated than in this study. ${ }^{18}$ In these circumstances the brain is receiving a substantial contribution of tryptamine from peripheral sources including intestinal bacteria. Thus, the peripheral contribution to brain tryptamine is important after a tryptophan load and presumably there is also some contribution in physiological circumstances. In rats tryptamine that is synthesised peripherally is partly responsible for the behavioural effects seen when rats are given tryptophan plus a monoamine oxidase inhibitor. ${ }^{19}$ Although peripheral decarboxylase inhibitors, which decrease peripheral tryptamine synthesis, cause no overt behavioural changes in humans, it may be that peripherally synthesised tryptamine has some small role to play in normal brain function.

Our data suggest that small and large tryptophan loads have similar effects on brain 5HT metabolism but that the large loads affect brain tryptamine metabolism more. This is interesting because we have suggested that the antidepressant action of tryptophan depends critically upon the dose used. ${ }^{13}$ We have suggested that $3 \mathrm{~g}$ given twice a day does have an antidepressant effect in unipolar depressed patients whereas $6 \mathrm{~g}$ given twice a day does not. As far as metabolic effects on indoleamine metabolism are concerned, the high and low dosage schedules seem to differ primarily in their effect on tryptamine synthesis. Thus, one hypothesis to explain the differential clinical effects of the large and small load would be that at high doses of tryptophan the elevated brain tryptamine levels in some way antagonise the elevated 5HT function b-ought about by elevated 5HT synthesis. One possible mechanism by which tryptamine could act to antagonise 5HT function would be to act together with $5 \mathrm{HT}$ on presynaptic 5HT receptors thus inhibiting firing of 5HT neurons and preventing release of $5 \mathrm{HT}$ onto postsynaptic receptors.

\section{Conclusions}

In human CNS, indoleamine metabolism is controlled in part by tryptophan availability. This is true both in physiological circumstance ${ }^{3}$ and after 
a tryptophan load. Presumably this would be true for dietary as well as pharmacological loads of tryptophan. Tryptamine metabolism is more sensitive than 5HT metabolism to changes in tryptophan levels and thus a tryptophan load can increase tryptamine synthesis more than 5HT synthesis. In control subjects lumbar CSF IAA is $15 \%$ of lumbar CSF 5HIAA but eight hours after a $6 \mathrm{~g}$ tryptophan load the value has risen to $40 \%$ (figs 3 and 4). Our data on the rat indicate that the relative amounts of the metabolites in CSF reflect the relative rates of metabolism of the amines. ${ }^{9}$ Thus, even if the tryptophan content of human brain is very small compared with that of $5 \mathrm{HT}$ its rate of metabolism can be of the same order of magnitude. The functional significance of tryptamine in human CNS is unknown and merits further investigation.

We thank Fong Kun Chan for excellent technical assistance. We are most grateful to the staff of the Radiology and Anaesthesia Departments of the Montreal Neurological Hospital whose help and co-operation made this study possible.

This investigation was supported by a grant from the Medical Research Council of Canada. A preliminary report of part of this work was presented at a meeting on Serotonin: Current Aspects of Neurochemistry and Function held in Athens, Greece, in September 1979.

\section{References}

1 Curzon G, Kantamaneni BD, Bartlett JR, Bridges PK. Transmitter precursors and metabolites in human ventricular cerebrospinal fluid. J Neurochem 1976; 26:613-5.

2 Vapalaliti M, Hyyppä MT, Nieminen V, Rinne UK. Brain monoamine metabolites and tryptophan in ventricular CSF of patients with spasm after aneurysm surgery. J Neurosurg 1978; 48: 58-63.

3 Young SN, Gauthier S, Anderson GM, Purdy WC. Tryptophan, 5-hydroxyindoleacetic acid and indoleacetic acid in human cerebrospinal fluid: interrelationships and the influence of age, sex, epilepsy and anticonvulsant drugs. $J$ Neurol Neurosurg Psychiatry 1980; 43:438-45.

4 Young SN, Etienne P, Sourkes TL. The relationship between rat brain and cisternal CSF tryptophan concentrations. J Neurol Neurosurg Psychiatry 1976; 39:239-43.

5 Garelis E, Young SN, Lal S, Sourkes TL. Monoamine metabolites in lumbar CSF: their sites of origin in relation to clinical studies. Brain Res 1974; 79:1-8.

6 Elbert MH, Perlow MJ. Utility of cerebrospinal fluid measurements in studies of brain monoamines. In: Usdin E, Weiner N, Youdim M B H, eds. Structure and Further of Monoamine Enzymes. New York: Marcel Dekker 1977: 963-84.

7 Eccleston D, Ashcroft GW, Crawford TBB, Stanton JB, Wood D, McTurk PH. Effect of tryptophan administration on 5HIAA in cerebrospinal fluid in man. J Neurol Neurosurg Psychiatry 1970; 33:269-72.

8 Ashcroft GW, Crawford TBB, Cundall RL, et al. 5-Hydroxytryptamine metabolism in affective illness: the effect of tryptophan administration. Psychol Med 1973; 3:326-32.

9 Young SN, Anderson GM, Purdy WC. Indoleamine metabolism in rat brain studied through measurements of tryptophan, 5-hydroxyindoleacetic acid and indoleacetic acid in cerebrospinal fluid. J Neurochem 1980; 34:309-15.

10 Jakupčević M, Lacković Z, Stefoski D, Bulat M, Nonhomogeneous distribution of 5-hydroxyindoleacetic acid and homovanillic acid in the lumbar cerebrospinal fluid of man. J Neurol Sci 1977; 31:165-71.

11 Anderson GM, Purdy WC. Liquid chromatographic-fluorometric system for the determination of indoles in physiological samples. Anal Chem 1979; 51:283-6.

12 Denckla WD, Dewey HK. The determination of tryptophan in plasma, liver and urine. $J$ Lab Clin Med 1967; 69:160-9.

13 Chouinard G, Young SN, Annable L, Sourkes TL. Tryptophan-nicotinamide imipramine and their combination in depression: a controlled study. Acta Psychiatr Scand 1979; 59:395-414.

14 Etienne P, Young SN, Sourkes TL. Inhibition by albumin of tryptophan uptake by rat brain. Nature 1976; 262:144-5.

15 Grahame-Smith DG. Studies in vivo on the relationship between brain tryptophan, brain 5HT synthesis and hyperactivity in rats treated with a monoamine oxidase inhibitor and L-tryptophan. J Neurochem 1971; 18:1053-66.

16 Friedman PA, Kappelman AH, Kaufman S. Partial purification and characterization of tryptophan hydroxylase from rabbit hindbrain $\mathrm{J}$ Biol Chem 1972; 247:4165-73.

17 Young SN, Anderson GM, Gauthier S, Purdy WC. The origin of indoleacetic acid and indolepropionic acid in rat and human cerebrospinal fluid. J Neurochem 1980; 34:1087-92.

18 Young SN, Lal S. CNS tryptamine metabolism in hepatic coma. J Neural Trans 1980 ; 47:153-61.

19 Marsden CA, Curzon G. The contribution of tryptamine to the behavioural effects of L-tryptophan in tranylcypromine-treated rats. Psychopharmacol 1978; 57:71-6. 